\title{
Rheumatoid meningitis
}

\section{A case report and review of the literature}

Zhaoyi Qin, MD, June Kim, MD, Damian Valencia, MD, Lames Hamoodi, MD, Jenna Neltner, MD,
Travis Sizemore, DO, MPH, and Robert Lightfoot Jr, MD
Correspondence

Dr. Valencia

damian.valencia@wright.edu

Neurology: Clinical Practice February 2020 vol. 10 no. 1 73-83 doi:10.1212/CPJ.0000000000000678

\section{Abstract \\ Purpose of review}

Rheumatoid arthritis is a systemic inflammatory disorder, which can involve many organs; among which, CNS involvement, as in rheumatoid meningitis (RM), is rare and difficult to recognize. Our goal is to present collective data of RM cases to better characterize this disease process and to start new discussions about pathophysiology, diagnosis, and treatment.

\section{Recent findings}

Since Kato et al., 39 cases of RM have been reported. Approximately 59\% were women, presenting with neurologic deficits (56\%) and diagnosed by MRI findings, leptomeningeal enhancement (69\%), after CSF analysis. Seventy-four percent were treated with corticosteroids, $64 \%$ as maintenance therapy, with $46 \%$ experiencing improvement or resolution in symptoms without relapse.

\section{Summary}

Diagnosis and prognosis of RM has drastically changed since the year 2000. Early detection with CSF and MRI or biopsy findings, coupled with early treatment using corticosteroids and immunologic therapy, has reduced mortality in this population.

Rheumatoid arthritis (RA) is a systemic inflammatory disorder, which can involve many different organ systems; among them, CNS involvement is less common and more difficult to recognize clinically. Rheumatoid meningitis (RM) is a rare CNS manifestation that can occur in RA. There have been scattered case reports describing its clinical, radiologic, and pathologic features, treatments, and outcomes. However, early recognition and identification of this entity is still lacking. Kato et al. ${ }^{3}$ focused on a Japanese case and reviewed an additional 21 cases (table 1) reported before the year 2000 for a collective description of RM. A majority of the patients in that review died, either without treatment or with failure of corticosteroid therapy. The diagnosis and prognosis of RM changed dramatically after that report. Here, we present another case and review of 38 cases reported since Kato's, hoping to present a clearer picture of this entity and to start a new discussion about its pathophysiology, diagnosis, and treatment options.

\section{Case}

A 63-year-old white woman presented with a 3-month history of frequent intermittent episodes of speech disturbance, confusion, and right-sided weakness. Symptoms progressively 
Table 1 General patient characteristics and disease history

\begin{tabular}{|c|c|c|c|c|c|c|c|c|c|c|c|c|}
\hline \multirow{2}{*}{$\begin{array}{l}\text { Citation } \\
\text { no. }\end{array}$} & \multirow{2}{*}{$\begin{array}{l}\text { Case } \\
\text { no. }\end{array}$} & \multirow[b]{2}{*}{ Year } & \multirow[b]{2}{*}{ Sex } & \multirow{2}{*}{$\begin{array}{l}\text { Age } \\
\text { (yrs) }\end{array}$} & \multirow{2}{*}{$\begin{array}{l}\text { RA } \\
\text { duration } \\
\text { (yrs) }\end{array}$} & \multirow{2}{*}{$\begin{array}{l}\mathrm{RF}(\mathrm{IU} / \\
\mathrm{mL})\end{array}$} & \multirow{2}{*}{$\begin{array}{l}\text { Anti-CCP } \\
(\mathrm{U} / \mathrm{mL})\end{array}$} & \multirow{2}{*}{$\begin{array}{l}\text { Extra-articular } \\
\text { manifestations }\end{array}$} & \multicolumn{3}{|c|}{$\begin{array}{l}\text { Treatment (6-12 mo before } \\
\text { presentation) }\end{array}$} & \multirow{2}{*}{$\begin{array}{l}\text { Active } \\
\text { synovitis }\end{array}$} \\
\hline & & & & & & & & & nbDMARD & bDMARD & Corticosteroid & \\
\hline 1 & 1 & 2001 & M & 52 & 2 & Positive & NR & RN & MTX, HCQ & NR & Yes & Yes \\
\hline 2 & 2 & 2001 & $\mathrm{~F}$ & 49 & 8 & 167 & NR & RN & NR & NR & NR & NR \\
\hline 2 & 3 & 2001 & $\mathrm{~F}$ & 65 & 10 & 313 & NR & RN & MTX & NR & NR & NR \\
\hline 3 & 4 & 2003 & $\mathrm{~F}$ & 71 & 20 & 320 & NR & PCD, AAS & MTX, SASP & NR & Yes & No \\
\hline 4 & 5 & 2005 & $\mathrm{~F}$ & 78 & 10 & 100 & NR & NR & MTX, LFT & NR & Yes & No \\
\hline 5 & 6 & 2005 & $\mathrm{~F}$ & 78 & 10 & 100 & NR & RN & MTX, LFT & NR & Yes & NR \\
\hline 6 & 7 & 2006 & M & 77 & 20 & NR & NR & NR & $\begin{array}{l}\text { MTX, HCQ, } \\
\text { SSZ, MIN }\end{array}$ & ADA & NR & NR \\
\hline 7 & 8 & 2006 & $\mathrm{~F}$ & 68 & NR & 109 & NR & NR & AZA, CYA & NR & Yes & Yes \\
\hline 8 & 9 & 2006 & $\mathrm{~F}$ & 58 & 0 & 413 & 12 & $N R$ & NR & NR & NR & NR \\
\hline 9 & 10 & 2006 & M & 71 & 2.5 & High & NR & NR & NR & NR & NR & No \\
\hline 10 & 11 & 2007 & M & 67 & 0 & 880 & Negative & NS & NR & NR & NR & No \\
\hline 10 & 12 & 2007 & $\mathrm{~F}$ & 76 & NR & Positive & Positive & NR & MTX & IFX & Yes & NR \\
\hline 11 & 13 & 2009 & $\mathrm{~F}$ & 53 & 3 & 1000 & NR & NR & MTX & NR & Yes & No \\
\hline 12 & 14 & 2009 & $M$ & 64 & 14 & Positive & Positive & NR & MTX & IFX & NR & NR \\
\hline 13 & 15 & 2009 & $\mathrm{~F}$ & 74 & 4 & Positive & 447.2 & NR & NR & NR & NR & NR \\
\hline 14 & 16 & 2009 & $\mathrm{~F}$ & 63 & 12 & NR & NR & NR & $\begin{array}{l}\text { MTX, HCQ, } \\
\text { SSZ }\end{array}$ & NR & Yes & No \\
\hline 15 & 17 & 2009 & M & 68 & NR & 50 & NR & NR & NR & NR & NR & NR \\
\hline 16 & 18 & 2010 & $\mathrm{~F}$ & 80 & 20 & NR & NR & NR & SASP, BU & ETN & Yes & No \\
\hline 17 & 19 & 2010 & M & 56 & 0.2 & 18 & Positive & NR & MTX, SASP & NR & NR & No \\
\hline 18 & 20 & 2011 & M & 70 & 20 & 108 & NR & NR & NR & NR & NR & NR \\
\hline 19 & 21 & 2011 & $\mathrm{~F}$ & 80 & NR & $<20$ & NR & NR & $\mathrm{HCQ}$ & NR & Yes & NR \\
\hline 20 & 22 & 2011 & M & 66 & 0 & Positive & 1448 & NR & NR & NR & NR & NR \\
\hline 21 & 23 & 2011 & $\mathrm{~F}$ & 71 & 15 & 27.9 & NR & NR & NR & NR & NR & No \\
\hline 22 & 24 & 2012 & $\mathrm{~F}$ & 62 & 4 & 351 & 120 & NR & MTX & NR & Yes & NR \\
\hline 23 & 25 & 2012 & $\mathrm{~F}$ & 58 & 1 & NR & NR & NR & MTX & $A D A$ & NR & No \\
\hline 24 & 26 & 2013 & M & 62 & 10 & NR & 760 & NR & None & None & None & No \\
\hline 25 & 27 & 2014 & $M$ & 59 & NR & NR & $N R$ & $N R$ & NR & $N R$ & NR & NR \\
\hline 26 & 28 & 2014 & M & 68 & 10 & NR & NR & NR & NR & NR & Yes & No \\
\hline 27 & 29 & 2014 & M & 70 & Chronic & Positive & NR & NR & NR & NR & NR & Yes \\
\hline 28 & 30 & 2014 & $\mathrm{~F}$ & 56 & NR & NR & NR & NR & None & NR & NR & Yes \\
\hline 29 & 31 & 2015 & $\mathrm{~F}$ & 63 & 9 & NR & NR & NR & None & NR & NR & NR \\
\hline 30 & 32 & 2016 & $M$ & 37 & 0 & 83 & $>250$ & NR & NR & NR & NR & NR \\
\hline 30 & 33 & 2016 & $\mathrm{~F}$ & 62 & 1 & NR & NR & NR & NR & NR & NR & NR \\
\hline 31 & 34 & 2016 & $\mathrm{~F}$ & 63 & NR & NR & NR & NR & NR & $\begin{array}{l}\text { Anti- } \\
\text { TNFa }\end{array}$ & Yes & NR \\
\hline 32 & 35 & 2016 & $\mathrm{~F}$ & 71 & 6 & 79 & 266 & RN & MTX & ADA & NR & No \\
\hline
\end{tabular}


Table 1 General patient characteristics and disease history (continued)

\begin{tabular}{|c|c|c|c|c|c|c|c|c|c|c|c|c|}
\hline \multirow{2}{*}{$\begin{array}{l}\text { Citation } \\
\text { no. }\end{array}$} & \multirow{2}{*}{$\begin{array}{l}\text { Case } \\
\text { no. }\end{array}$} & \multirow[b]{2}{*}{ Year } & \multirow[b]{2}{*}{ Sex } & \multirow{2}{*}{$\begin{array}{l}\text { Age } \\
\text { (yrs) }\end{array}$} & \multirow{2}{*}{$\begin{array}{l}\text { RA } \\
\text { duration } \\
\text { (yrs) }\end{array}$} & \multirow{2}{*}{$\begin{array}{l}\mathrm{RF}(\mathrm{IU} / \\
\mathrm{mL})\end{array}$} & \multirow{2}{*}{$\begin{array}{l}\text { Anti-CCP } \\
(\mathrm{U} / \mathrm{mL})\end{array}$} & \multirow{2}{*}{$\begin{array}{l}\text { Extra-articular } \\
\text { manifestations }\end{array}$} & \multicolumn{3}{|c|}{$\begin{array}{l}\text { Treatment ( } 6-12 \text { mo before } \\
\text { presentation) }\end{array}$} & \multirow{2}{*}{$\begin{array}{l}\text { Active } \\
\text { synovitis }\end{array}$} \\
\hline & & & & & & & & & nbDMARD & bDMARD & Corticosteroid & \\
\hline 33 & 36 & 2016 & $\mathrm{~F}$ & 66 & 12 & Positive & Positive & NR & MTX & IFX & NR & NR \\
\hline Current & $37^{a}$ & 2016 & $\mathrm{~F}$ & 63 & $>7$ & 632 & $>200$ & NR & None & $\mathrm{ADA}$ & Yes & No \\
\hline 34 & 38 & 2017 & M & 59 & 6 & Positive & Positive & NR & MTX & None & No & No \\
\hline 35 & 39 & 2017 & $M$ & 65 & 0.6 & 12 & 275 & NR & MTX & ETN & Yes & No \\
\hline
\end{tabular}

Abbreviations: $\mathrm{AAS}=$ atlantoaxial subluxation; $\mathrm{ADA}=$ adalimumab; $\mathrm{AZA}=$ azathioprine; $\mathrm{BU}=$ bucillamine; $\mathrm{CCP}=\mathrm{citrullinated}$ peptide; $\mathrm{CS}=\mathrm{corticosteroid}$ : $\mathrm{CYA}=$ cyclosporin; ETN = etanercept; HCQ = hydroxychloroquine; IFX = infliximab; LFT = leflunomide; MIN = minocycline; MMF = mycophenolate mofetil; MTX = methotrexate; NR = not reported; NS = necrotizing scleritis; PCD = pericarditis; RN = rheumatoid nodule; RTX = rituximab; SASP = salazosulfapyridine; SSZ = sulfasalazine; $\mathrm{TCZ}=$ tocilizumab.

aThe present case.

worsened and eventually became persistent 2 days before her presentation. These episodes had previously been diagnosed clinically as TIAs and possible focal seizures. She had been empirically started on an antiepileptic regimen, although several EEG studies during the episodes were negative for seizure-like activity. This patient had previously been on methotrexate for RA diagnosed 7 years earlier, which was discontinued by the patient for supposed lack of efficacy after 4 months of therapy. The patient was started on a tumor necrosis factor alpha (TNF $\alpha)$ inhibitor, adalimumab, 2

Figure 1 FLAIR MRI
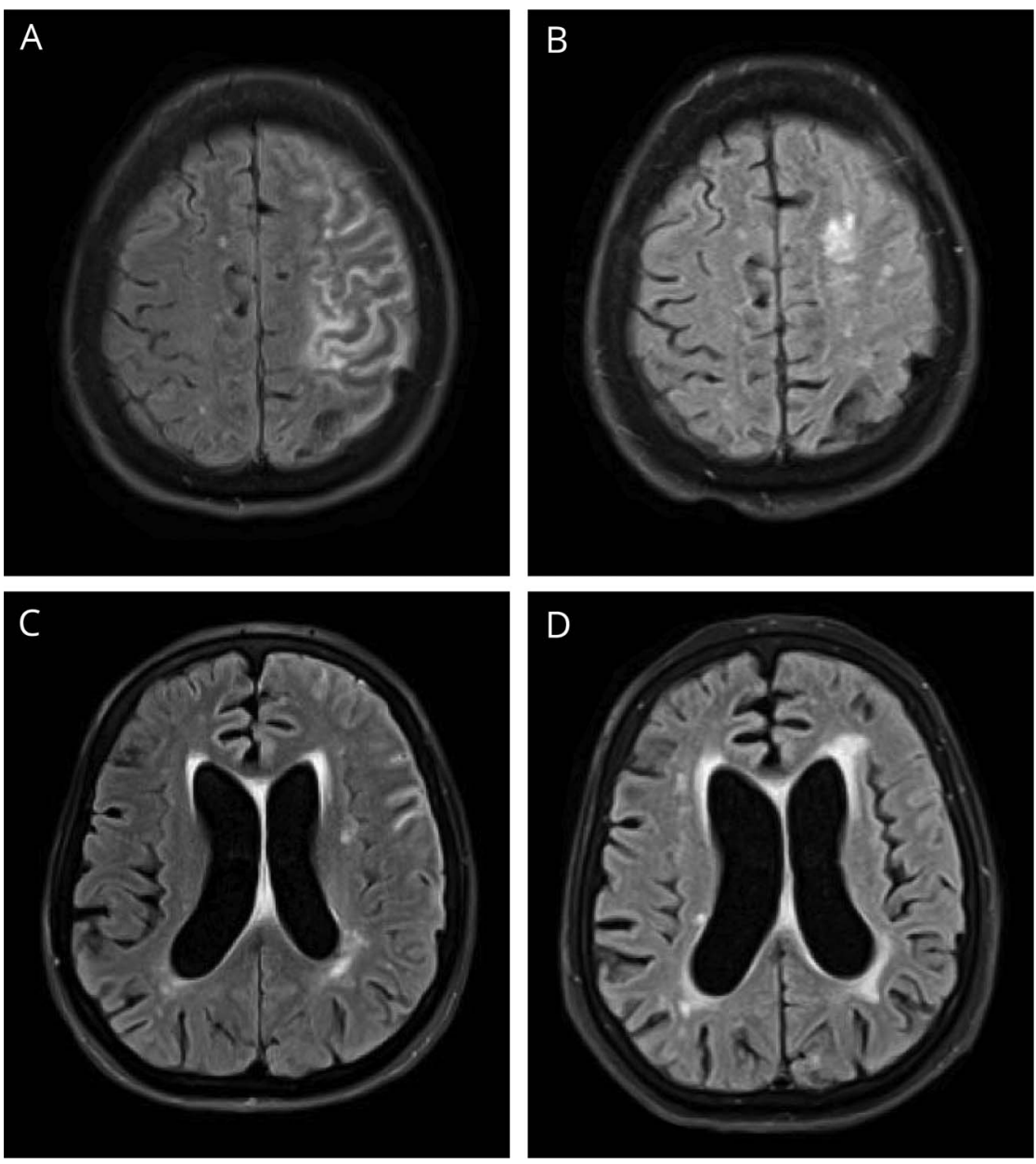

Noncontrast FLAIR MRI of the head, axial section. For interval comparison, images $A$ and $C$ are from November 11, 2016, and (B and D) from April 18, 2017. (A) Sulcal hyperintense signal compatible with meningitis with mild amount of hyperintense signal in subcortical white matter of the frontal and parietal lobes suggesting inflammation or infection. (B) Significantly decreased sulcal hyperintense signal in the left cerebral hemisphere with mild amount of remaining hyperintensity in superior portions of the left frontal and parietal lobes. (C) Sulcal hyperintense signal with mildly enlarged lateral ventricles. (D) Sulcal hyperintense signal is no longer seen, but still with mildly enlarged lateral ventricles. There is mildly increased amount of periventricular white matter FLAIR hyperintense signal. 

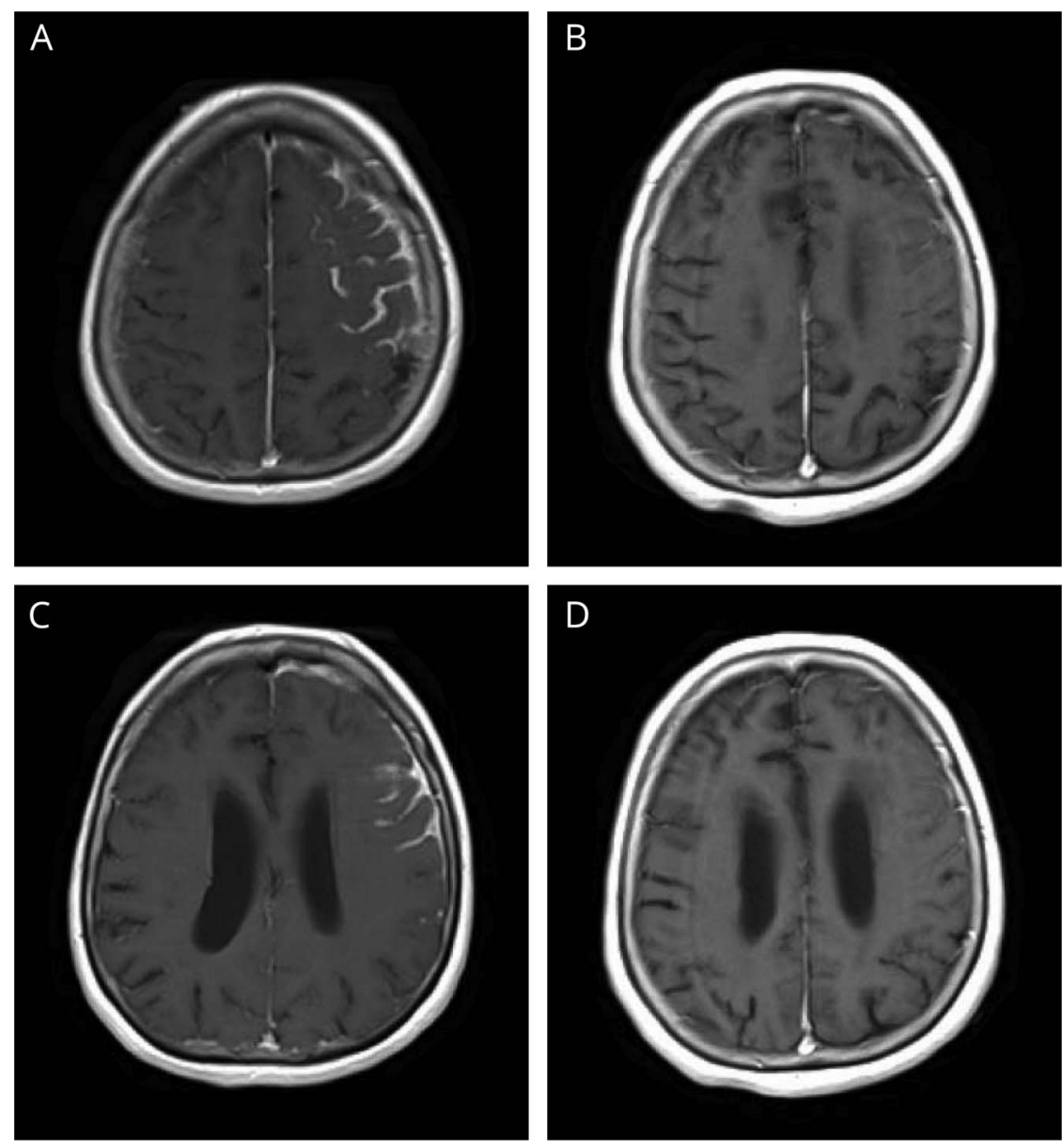

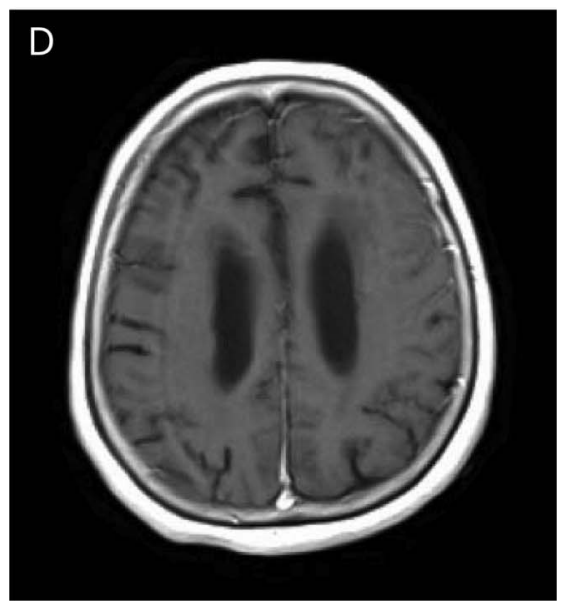

Contrast T1-weighted MRI of the head, axial section. For interval comparison, images $A$ and $C$ are from November 11, 2016, and (B and D) from April 18, 2017. (A and C) Leptomeningeal and pachymeningeal enhancement are seen in the left frontal lobe. (B) Resolution of previous enhancement with continued mild sulcal effacement in the left frontal and parietal lobes. (D) Minimal remaining leptomeningeal enhancement when compared with prior. months before presentation, receiving 2 doses before her admission. On physical examination, the patient was noted to have dysphasia, confusion, right-sided weakness, and right lower extremity clonus. There was chronic synovial thickening involving all metacarpophalangeal (MCP) joints, deformities in both hands with MCP subluxation, and ulnar deviation. No active synovitis or rheumatoid nodules were detected clinically.

On laboratory workup, the patient had a rheumatoid factor (RF) level of $632 \mathrm{IU} / \mathrm{mL}$ and an anti-citrullinated peptide level of $>200 \mathrm{U} / \mathrm{mL}$. Inflammatory markers were also elevated, with an erythrocyte sedimentation rate of $59 \mathrm{~mm} / \mathrm{s}$ and c-reactive protein of $1.3 \mathrm{mg} / \mathrm{L}$. A total of 3 lumbar punctures were performed before and after this admission, all showing elevation in protein and lymphocytic pleocytosis. Initial CSF results are as follows: white blood cell count 71/ $\mu \mathrm{L}, 93 \%$ lymphocytes, protein $85 \mathrm{mg} / \mathrm{dL}$, and glucose 38 $\mathrm{mg} / \mathrm{dL}$. Noncontrast FLAIR MRI of the head showed sulcal hyperintense signal compatible with meningitis, also with a mild amount of hyperintense signal in subcortical white matter of the frontal and parietal lobes suggesting inflammation or infection (figures 1-2).
The patient underwent an extensive infectious disease workup, including tissue biopsy pathology and culture, CSF Gram stain and culture, rapid plasma reagin, Rickettsia IgG and IgM, human immunodeficiency virus $\mathrm{Ab}$-Ag screen, toxoplasma IgG and IgM, Aspergillus fumigatus IgE Ab, fungal serology, tuberculosis QuantiFERON, acid-fast stain and culture, varicella zoster virus PCR, John Cunningham polyomavirus PCR, and meningitis/encephalitis panel (Escherichia coli K1, Haemophilus influenzae, Listeria, Neisseria, Streptococcus agalactiae, Streptococcus pneumoniae, Cryptococcus, Cytomegalovirus, Enterovirus, human herpesvirus 6, herpes simplex virus 1 , herpes simplex virus 2 , human parechovirus, varicella-zoster virus, and Epstein-Barr virus PCR), which were all negative. Cervical spine radiographs were also obtained to rule out atlantoaxial subluxation in the setting of right-sided extremity clonus.

Up to this point, the patient had been treated with ibuprofen and acetaminophen for persistent global headaches. Neurology had placed patient on levetiracetam for focal seizures and had been placed on low-dose oral prednisone for RA. Definitive diagnosis was made at 3 months via biopsy. Microscopic examination of the pia mater demonstrated 
necrotizing granulomatous inflammation, characterized by central necrosis with surrounding multinucleated giant cells, histiocytes, and marked lymphoplasmacytic inflammation, which is characteristic for rheumatoid nodules. The dura mater and brain parenchyma were involved as well (figure 3).

The patient was started on high-dose methylprednisolone 1,000 mg daily, which was subsequently switched to oral prednisone and rituximab $600 \mathrm{mg}$ IV weekly for 4 weeks. The patient was discharged after the first rituximab infusion. On discharge, the patient had significant improvement in her mental status, rightsided weakness, and near total resolution of the dysphasia and clonus. Repeat MRI 1 year after completing the rituximab course showed significantly decreased sulcal hyperintense signal in the left cerebral hemisphere with mild amount of remaining hyperintensity in superior portions of the left frontal and parietal lobes. There was a persistent and mildly increased amount of periventricular white matter FLAIR hyperintense signal (figures 1 and 2). The patient's symptoms were completely resolved at this time as well.

\section{Review of literature}

A thorough literature review of the term "rheumatoid meningitis" via PubMed identified 38 cases of RM in the English literature published from 2000 to 2017, all of which, plus the present case, are listed in table $1 .^{1-35}$

\section{Discussion}

In reviewing the reported cases of RM, approximately two-thirds (59\%) of the cases were women ( 23 women and 16 men), which is similar to the sex distribution ratio seen in RA. Patients were between the ages of 37 and 80 years, with a mean age of 65 years. Notably, not all patients had long-standing RA before the onset of RM. In this case review, 14 of the 31 (45\%) patients that had reported data about RA duration had less than 5 years of diagnosed RA before developing RM. Surprisingly, 5 of the 14 (36\%) patients mentioned previously did not have a diagnosis of RA before presentation with RM symptoms. In addition, it appeared that men had an earlier onset of RM in their RA course.
The diagnosis of RA is often delayed and may only occur many years after the onset of joint symptoms, especially in patients without regular primary care.

The median duration of RA before RM onset was 8.5 years among women and only 2 years among men. The diagnosis of RA is often delayed and may only occur many years after the onset of joint symptoms, especially in patients without regular primary care. Thus, it is difficult to assess whether this sex difference in onset is truly significant in such a small patient population. See table 1 for full list of patient demographics and disease history.

Extra-articular manifestations of RA were reported before diagnosis of RM in only 6 cases. We defined extra-articular manifestations as rheumatoid nodules in elbows, hands, and Achilles tendon, scleritis, pulmonary artery hypertension, pericarditis, and atlantoaxial dislocation. Of cases with relevant data available, all were seropositive. The majority of patients had an RF titer greater than $100 \mathrm{IU} / \mathrm{mL}$, with several even higher than $500 \mathrm{IU} / \mathrm{mL}$. In this case review, at the onset of RM, most patients had clinically inactive rheumatoid synovitis, making its diagnosis even more elusive. These patients were on a variety of therapies for RA within the year before RM onset, including biological and traditional diseasemodifying antirheumatic drugs and corticosteroids.

Presenting symptoms for RM are quite diverse. However, it appears that most of these cases share a common constellation of symptoms, which include headaches $(28 \%)$, confusion, TIA or stroke-like symptoms (56\%), seizure-like activity (33\%), and psychiatric symptoms. Symptoms usually began as episodic (44\%), becoming more persistent as the disease course progressed. The similarity of these symptoms

Figure 3 Brain biopsy
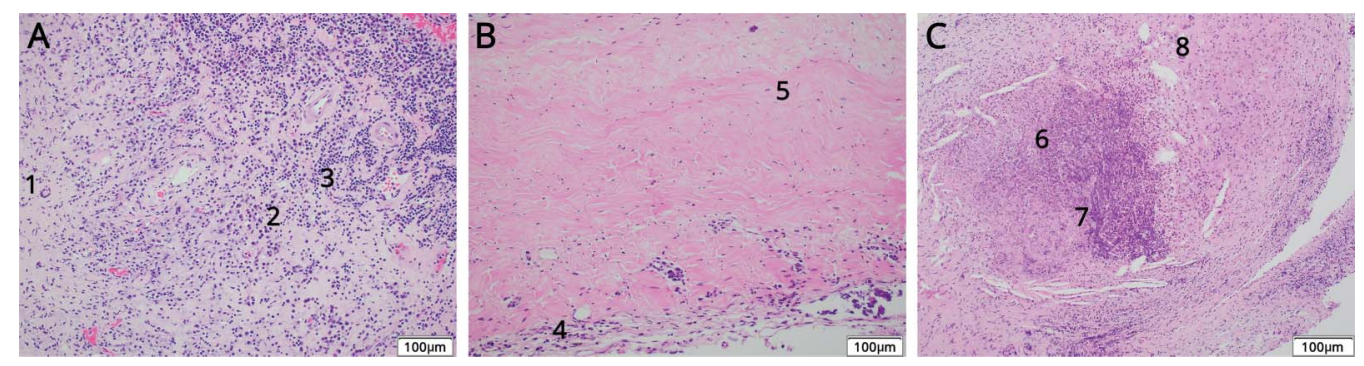

(A) Brain biopsy, which shows lymphoplasmacytic inflammation with multinucleated giant cells (1: multinucleated giant cells; 2: plasma cells; 3: lymphocytes). (B) Biopsy of the dura mater, which shows pachymeningitis with fibrous tissue thickening and hypertrophy with chronic inflammatory cells (4: inflammatory cells; 5: thickened connective tissue). (C) Biopsy of the pia mater, which shows a classic rheumatoid nodule; caseating granuloma with a necrotic center surrounded by inflammatory cells (6: inflammatory cells; 7: necrotic center; 8: multinucleated giant cell). 
Table 2 Patient presenting signs and diagnostic studies

\begin{tabular}{|c|c|c|c|c|c|c|c|c|c|c|c|c|}
\hline \multirow[b]{2}{*}{$\begin{array}{l}\text { Citation } \\
\text { no. }\end{array}$} & \multirow[b]{2}{*}{$\begin{array}{l}\text { Case } \\
\text { no. }\end{array}$} & \multicolumn{2}{|c|}{$\begin{array}{l}\text { Neurologic } \\
\text { symptoms }\end{array}$} & \multirow[b]{2}{*}{$\mathrm{HA}$} & \multirow[b]{2}{*}{ SZS } & \multirow[b]{2}{*}{ Confusion } & \multicolumn{3}{|l|}{ CSF findings } & \multicolumn{2}{|l|}{ Imagings } & \multirow[b]{2}{*}{ Biopsy } \\
\hline & & Episodic & TIA & & & & $\begin{array}{l}\text { WBC/ } \\
\text { lymphocytes }\end{array}$ & $\begin{array}{l}\text { Protein (mg/ } \\
\mathrm{dL} \text { ) }\end{array}$ & $\begin{array}{l}\text { Glucose (mg/ } \\
\mathrm{dL})\end{array}$ & $\begin{array}{l}\text { MRI } \\
\text { finding }\end{array}$ & Location & \\
\hline 1 & 1 & No & Yes & No & No & No & $8 / \mu \mathrm{L}$ & 53 & Normal level & LE & L frontal/parietal & PM \\
\hline 2 & 2 & No & No & Yes & No & Yes & NR & 250 & NR & $\mathrm{ME}$ & $\begin{array}{l}\text { b/l frontal/parietal/ } \\
\text { temporal }\end{array}$ & NR \\
\hline 2 & 3 & No & No & No & No & No & NR & 85 & NR & $\mathrm{ME}$ & b/l frontal/parietal & LM, RN \\
\hline 3 & 4 & No & No & Yes & No & Yes & $237 / \mu \mathrm{L}$ & 74 & NR & LE & R temporal/brainstem & LM \\
\hline 4 & 5 & Yes & Yes & No & No & No & $23 / \mu \mathrm{L}, 45 \%$ & 73 & Normal level & LE & R hemisphere & $\mathrm{RN}$ \\
\hline 5 & 6 & Yes & Yes & No & No & No & NR & High & NR & LE & NR & $\mathrm{RN}$ \\
\hline 7 & 8 & Yes & Yes & No & No & No & $6-9 / \mu \mathrm{L}$ & $56-71$ & Normal level & LE & NR & LM \\
\hline 8 & 9 & No & Yes & Yes & Yes & No & $N R$ & NR & NR & LE, PE & R hemisphere & $\begin{array}{l}\text { LM, PM, } \\
\text { RN }\end{array}$ \\
\hline 9 & 10 & Yes & Yes & No & No & No & Elevated & NR & NR & LE & b/l frontal/parietal & LM \\
\hline 10 & 11 & No & No & No & No & No & NR & NR & NR & $\mathrm{PE}$ & Diffuse & PM \\
\hline 10 & 12 & No & Yes & No & Yes & Yes & Normal level & NR & NR & LE & R hemisphere & PM, RN \\
\hline 11 & 13 & No & No & No & No & No & NR & NR & $N R$ & LE & Diffuse & LM \\
\hline 12 & 14 & Yes & No & No & Yes & No & $27 / \mu \mathrm{L}$ & $\mathrm{H}$ & NR & LE, PE & L parietal & LM \\
\hline 13 & 15 & No & No & No & Yes & Yes & NR & NR & NR & HSS & $\mathrm{R}$ frontal & LM, RN \\
\hline 15 & 17 & No & Yes & No & No & No & $7 / \mu \mathrm{L}$ & 38 & 60 & PE & Diffuse & PM \\
\hline 16 & 18 & Yes & Yes & No & No & No & $18 / \mu \mathrm{L}$ & 55 & NR & $\mathrm{ME}$ & L parietal & PM, RN \\
\hline 17 & 19 & No & No & No & Yes & No & $26 / \mu \mathrm{L}$ & 47 & NR & LE, HSS & $\mathrm{R}$ hemisphere & NR \\
\hline 18 & 20 & No & No & Yes & No & Yes & $140 / \mu \mathrm{L}$ & 267 & Normal level & $\mathrm{N}$ & NR & NR \\
\hline 19 & 21 & No & Yes & No & No & No & $12 / \mu \mathrm{L}, 78 \%$ & 77 & 60 & LE, PE & R frontal/parietal & PM, LM \\
\hline 20 & 22 & No & Yes & No & Yes & Yes & $11 / \mu \mathrm{L}$ & Normal level & Normal level & LE, HSS & NR & LM \\
\hline 21 & 23 & No & No & No & Yes & Yes & WNL & NR & NR & LE, PE & b/l frontal/parietal & $\mathrm{LM}, \mathrm{RN}$ \\
\hline 22 & 24 & No & Yes & Yes & No & No & $40 / \mu \mathrm{L}$ & 40 & NR & ME, HSS & $\mathrm{R}$ frontal/parietal & NR \\
\hline 23 & 25 & No & No & Yes & Yes & No & $30 / \mu \mathrm{L}$ & 56 & NR & LE, PE & NR & LM, RN \\
\hline 24 & 26 & Yes & No & No & Yes & No & Normal level & NR & NR & HSS & $\begin{array}{l}\text { R frontal, L frontal/ } \\
\text { parietal }\end{array}$ & LM \\
\hline 25 & 27 & Yes & Yes & No & No & No & $30 / \mu \mathrm{L}, 64 \%$ & 75 & Normal level & NR & NR & NR \\
\hline 26 & 28 & No & No & No & No & No & $13 / \mu \mathrm{L}$ & 75 & Normal level & $\mathrm{ME}$ & Diffuse & $\mathrm{RN}$ \\
\hline 27 & 29 & Yes & Yes & No & No & No & $68 / \mu \mathrm{L}$ & Normal level & Normal level & LE, PE & L hemisphere & $N R$ \\
\hline 28 & 30 & No & No & No & Yes & No & $N R$ & NR & NR & NR & b/l frontal & $\mathrm{RN}, \mathrm{PM}$ \\
\hline 29 & 31 & No & Yes & Yes & No & No & NR & NR & NR & LE & Parafalcine & $\mathrm{RN}$ \\
\hline 30 & 32 & Yes & Yes & Yes & No & No & $10 / \mu \mathrm{L}, 96 \%$ & $50->16$ & NR & LE & L frontal/parietal & $\mathrm{RN}, \mathrm{LP}$ \\
\hline 30 & 33 & Yes & No & No & Yes & Yes & NR & NR & $N R$ & LE & Diffuse & RN, LM \\
\hline
\end{tabular}


Table 2 Patient presenting signs and diagnostic studies (continued)

\begin{tabular}{|c|c|c|c|c|c|c|c|c|c|c|c|c|}
\hline \multirow[b]{2}{*}{$\begin{array}{l}\text { Citation } \\
\text { no. }\end{array}$} & \multirow[b]{2}{*}{$\begin{array}{l}\text { Case } \\
\text { no. }\end{array}$} & \multicolumn{2}{|c|}{$\begin{array}{l}\text { Neurologic } \\
\text { symptoms }\end{array}$} & \multirow[b]{2}{*}{$\mathrm{HA}$} & \multirow[b]{2}{*}{ SZS } & \multirow[b]{2}{*}{ Confusion } & \multicolumn{3}{|l|}{ CSF findings } & \multicolumn{2}{|c|}{ Imagings } & \multirow[b]{2}{*}{ Biopsy } \\
\hline & & Episodic & TIA & & & & $\begin{array}{l}\text { WBC/ } \\
\text { lymphocytes }\end{array}$ & $\begin{array}{l}\text { Protein (mg/ } \\
\mathrm{dL})\end{array}$ & $\begin{array}{l}\text { Glucose (mg/ } \\
\mathrm{dL})\end{array}$ & $\begin{array}{l}\text { MRI } \\
\text { finding }\end{array}$ & Location & \\
\hline 32 & 35 & Yes & Yes & Yes & No & Yes & $50-80 / \mu \mathrm{L},>95 \%$ & $46-67$ & Low & LE & $L$ frontal & $\mathrm{LM}, \mathrm{RN}$ \\
\hline 33 & 36 & Yes & Yes & No & No & No & $213 / \mu L, 86 \%$ & 85.9 & NR & LE & B frontal & PM \\
\hline Current & $37^{a}$ & Yes & Yes & Yes & Yes & Yes & $71 / \mu \mathrm{L}, 93 \%$ & 85 & 38 & LE, PE & $\begin{array}{l}\text { L frontal/parietal/ } \\
\text { temporal }\end{array}$ & NR \\
\hline 34 & 38 & Yes & Yes & No & No & No & $30 / \mu \mathrm{L}, 64 \%$ & 75 & 58 & LE & R frontal & $\mathrm{RM}$ \\
\hline 35 & 39 & Yes & No & No & Yes & No & $12 / \mu \mathrm{L}$ & 32 & 55 & LE & b/l frontal, L parietal & LM \\
\hline
\end{tabular}

Abbreviations: $C T X=$ corticosteroids; $H A$ = headache; HSS = hyperintense signal; $L=$ left; $L E=$ leptomeningeal enhancement; $L M=$ leptomeningitis; $L P=$ lumbar puncture; $\mathrm{ME}=$ meningeal enhancement (not specified); $\mathrm{MV}=$ meningeal vasculitis; $\mathrm{NR}=$ not reported; $\mathrm{PE}=$ pachymeningeal enhancement; $\mathrm{PM}=$ pachymeningitis; R = right; RN = rheumatoid nodule; RM = rheumatoid meningitis; SZS = seizures; WBC = white blood cell; WNL = within normal limits. The present case.

to other neurologic disorders, especially TIAs, poses a great challenge for the early recognition and diagnosis of RM, especially as the leading decade of RA onset is the 60s in women and the 70s in men. Diagnosis was established by CSF and MRI findings. Eight of the 39 cases were not confirmed by biopsy. The patient described in this case had multiple TIA events with consistent symptoms every 2 weeks, visiting the emergency department several times, with 2 hospitalizations. Initially, the patient was diagnosed with a TIA; later, the diagnosis was changed to "focal seizures." It was not until 3 months after the patient's initial presentation that the diagnosis of RM was made. At this point in time, the patient had become more confused and had persistent symptoms.

Raising awareness for RM in the primary care setting, emergency departments, and neurology services is essential for early recognition, diagnosis, and appropriate treatment in this patient population. Thus, it is imperative that clinicians include RM in the differential for any patient with RA and a history of recurrent TIA-like symptoms or unexplained neurologic findings. Other features that may support a diagnosis of RM are described below.

A majority of the patients have elevated systemic inflammatory markers erythrocyte sedimentation rate or C-reactive protein independent of RA disease activity. The most typical finding on CSF analysis is lymphocytic pleocytosis. However, this CSF finding can be dependent on the phase of the disease. There are cases that report serial CSF studies in which the fluid initially neutrophil dominant converted to monocyte dominant later in the disease course. Only 3 cases reported a normal cell count, whereas a majority of the cases had an elevated CSF protein level. The findings mentioned here are consistent with meningitis and share qualities with chemistry findings in RA pleural fluid and pericardial fluid.

Leptomeningeal enhancement to gadolinium was the most commonly seen abnormality on MRI (69\%), followed by dural/ pachymeningeal and pachymeningeal with leptomeningeal enhancement. Several cases also reported hyperintense signal in subarachnoid space on FLAIR images. Other reported changes include edema, intracranial lesions, optic nerve enhancement, and enlarged ventricles. There are several less common abnormalities that are more than likely incidental findings and are unrelated to the conversation at present. Also, we are summarizing and comparing these cases from radiology reports rather than image interpretation directly. Thus, it is difficult to assess the accuracy of categorization. For instance, when "meningeal enhancement" is described, it may mean leptomeningeal or dural/pachymeningeal enhancement. In the present case, the clinical MRI report described only leptomeningeal enhancement; however, on further evaluation, a different radiologist reported pachymeningeal enhancement as well. A full list of patient presenting signs and study findings is available in table 2 .

The most common finding on pathology was chronic inflammation (leptomeningeal and/or pachymeningeal when the dura mater is involved and sampled), as the name of RM dictates. This is consistent with the autopsy findings in Kato's case review that studied reports before the year of 2000. Another key feature described in Kato's review of pathology was the presence of rheumatoid nodules, which were reported in 12 of the 24 cases presented. In our review, a similar percentage of cases demonstrated the classic necrotizing center surrounded by multinucleated giant cells and inflammatory cells, as did our case. After infectious etiologies are ruled out, the differential diagnosis for necrotizing granulomas would favor rheumatoid nodules as the most likely explanation. Our case shows pathologic findings characteristic of rheumatoid nodules in the leptomeninges, described in the pathology report as necrotizing granulomatous change. Vasculitis was reported in about half of the cases in our review of the literature, in accordance with the key histologic features predominantly encountered (rheumatoid nodules, lymphocytic infiltration, and vasculitis) for RM. Early studies by Sokoloff et al. ${ }^{36}$ suggested that early biopsies of rheumatoid nodules show vasculocentricity and that they may simply be one histologic manifestation of rheumatoid vasculitis. 
As a local manifestation of a systemic inflammatory condition, the pathophysiology of rheumatoid meningitis is consistent with that of rheumatoid arthritis.

Of note, it is not possible to differentiate aseptic from infectious meningitis on imaging alone, with certain meningeal neoplastic lesions also mimicking this clinical picture. It is imperative to obtain thorough serum studies and pathology with special stains, cultures, and PCR to establish a diagnosis of RM. In the dominant age groups in which RA begins, there can be many unrelated neurologic conditions causing symptoms or abnormal imaging findings. In addition, the sensitivity of currently available imaging technology such as MRI in detecting meningeal involvement is unknown. This suggests that any patient with RA having neurologic symptoms may warrant spinal fluid examination, both to detect radiologically undetected RM and to rule out infectious and other etiologies.

Of the 33 cases with reported outcomes, only 1 patient had recurrent disease and died. All other patients had improvement or complete clinical resolution of symptoms. Many of the cases reported also demonstrated radiologic improvement or resolution with treatment. In regard to therapy, 29 of 39 (74\%) patients were initially treated with corticosteroids, with $64 \%$ of patients being placed on corticosteroids for maintenance therapy. Of those on corticosteroid maintenance therapy, $46 \%$ had improvement or resolution of symptoms without relapse. See table 3 for full detail regarding treatment and response. As mentioned, the prognosis of RM has drastically improved compared with outcomes reported before the year 2000. The majority of cases reported by Kato et al. ${ }^{3}$ were diagnosed at autopsy rather than by biopsy. Our study found that patients were presenting for evaluation between 1 day and 13 months of symptom onset, with MRI soon after presentation (although time to MRI was not consistently reported). Biopsy was performed as early as 13 days from presentation to as late as 361 days. We would like to attribute this change in prognosis to earlier diagnosis from more readily available MRI, more aggressive use of immunosuppressants, including biologic agents, and the overall improvement in hospital care. However, key pharmacologic treatments including immediate and subsequent maintenance regimens have not been established yet. Treatment choices have been case based and dependent on the physician's, usually neurologist or rheumatologist, personal experience. This review summarizes the success or failure of therapy within each case reported.
As a local manifestation of a systemic inflammatory condition, the pathophysiology of RM is consistent with that of RA. Generalized and targeted therapy is also similar, only more aggressive in the case of RM. In this review, most of the reported cases had pulse steroid therapy as initial treatment, with differing follow-up maintenance regimens. Two patients had ineffective outcomes; 1 patient death and 1 experiencing permanent hearing loss. There were 15 cases treated with only corticosteroids; 1 patient became steroid dose dependent, and the others had appropriate clinical improvement. In 5 cases reported, patients receiving maintenance therapy with cyclophosphamide also experienced good outcomes. In one of the 5 cases previously mentioned, 1 patient initially had resolution of symptoms with cyclophosphamide, only to relapse during initiation of maintenance with infliximab. Cyclophosphamide was restarted with repeat resolution of symptoms. This may indicate some benefit to continued cyclophosphamide therapy over TNF inhibitors.

The present case had excellent results with rituximab, an antiCD20 monoclonal antibody. In the literature, we found 2 other cases reporting positive experiences with rituximab. To our knowledge, Schmidt et al. were the first to report rituximab use in $\mathrm{RM}^{14}$ Immunohistochemistry on the tissue biopsy performed on that case showed a high percentage of B lymphocytes expressing CD20. One cycle of rituximab ( 2 infusions of 1 $\mathrm{g}$ with an interval of 2 weeks between each infusion) was administered. The patient was tapered from corticosteroids over 3 months and required only methotrexate $15 \mathrm{mg} / \mathrm{wk}$ as maintenance treatment. That patient had complete remission of both RM and RA at 2-year follow-up. One later case published in 2017 reported a lack of response with initial rituximab therapy (dosage and course were not reported), but resolution of disease was observed with a second course of rituximab.

Anti-TNF agents have been shown to be effective treatment for the articular manifestations of RA, but there has been a lack of efficacy in cases of RM. In fact, there have been multiple reports of RM occurring in patients simultaneously receiving immunomodulatory therapy with anti-TNF agents. ${ }^{7,9,11,12,14,18,25,33}$ For instance, Ahmed et al. ${ }^{6}$ reported recurrence of neurologic symptoms after restarting of adalimumab in a patient with pachymeningitis, $\mathrm{Chou}^{8}$ reported recurrence of meningitis while the patient was on adalimumab, and Tsuzaki et al. ${ }^{35}$ reported a case occurring during etanercept treatment. It has been suggested that restricted diffusion of the high-molecularweight monoclonal antibodies across the blood-brain barrier might be contributing to the reports of meningitis in patients receiving anti-TNF agents. ${ }^{8}$

There are no reported cases with other targeted therapies. There is some speculation on the use of interleukin (IL) inhibitors. Several reports from Japan have evaluated cytokine levels in CSF and report a correlation between IL-6 levels and clinical symptoms. This raises the question to whether IL-6 inhibitors would be more effective than current therapy regimens. For the latest case reported in the 
Table 3 Patient therapeutic coarse and outcomes

\begin{tabular}{|c|c|c|c|c|c|}
\hline \multirow[b]{2}{*}{ Citation no. } & \multirow[b]{2}{*}{ Case no. } & \multicolumn{2}{|l|}{ Treatment } & \multicolumn{2}{|c|}{ Outcomes } \\
\hline & & Immediate & Maintenance & Clinical & Radiologic \\
\hline 1 & 1 & $\mathrm{CS}, \mathrm{CTX}$ & CS, HCQ, CTX & $\mathrm{R}$ & 1 \\
\hline 2 & 2 & Heparin & NR & $\mathrm{R}$ & NR \\
\hline 2 & 3 & VP shunt & NR & 1 & W \\
\hline 3 & 4 & $\mathrm{CS}$ & $\mathrm{CS}$ & Dc & NR \\
\hline 4 & 5 & CS & CS & 1 & 1 \\
\hline 5 & 6 & $\mathrm{CS}$ & NR & 1 & 1 \\
\hline 6 & 7 & CS & $\mathrm{CS}$ & $\mathrm{R}$ & 1 \\
\hline 7 & 8 & CTX & CTX, CS, MMF & $\mathrm{R}$ & 1 \\
\hline 8 & 9 & CTX, CS & CTX, CS & $\mathrm{R}$ & $\mathrm{R}$ \\
\hline 9 & 10 & CS, CTX, IVIG & NR & 1 & 1 \\
\hline 10 & 11 & $\mathrm{CS}$ & CS, MTX & NC & NR \\
\hline 10 & 12 & $\mathrm{CS}$ & $\mathrm{CS}$ & $1^{b}$ & NR \\
\hline 11 & 13 & CS & CS & $I^{b}$ & I \\
\hline 12 & 14 & RTX, CS & CS, MTX & $\mathrm{R}$ & $\mathrm{R}$ \\
\hline 13 & 15 & CS & NR & 1 & $\mathrm{R}$ \\
\hline 14 & 16 & CTX, CS & NR & 1 & 1 \\
\hline 15 & 17 & CS & CS & $\mathrm{R}$ & 1 \\
\hline 16 & 18 & $\mathrm{CS}$ & $\mathrm{CS}$ & 1 & 1 \\
\hline 17 & 19 & $\mathrm{CS}$ & $\mathrm{CS}$ & 1 & 1 \\
\hline 18 & 20 & $\mathrm{CS}$ & $\mathrm{CS}, \mathrm{AZA}$ & $\mathrm{R}$ & $\mathrm{R}$ \\
\hline 19 & 21 & NR & NR & NR & NR \\
\hline 20 & 22 & CS & CS & $\mathrm{R}$ & NR \\
\hline 21 & 23 & NR & CS, MTX & 1 & NR \\
\hline 22 & 24 & CS & CS, MTX & I & NR \\
\hline 23 & 25 & $\mathrm{CS}$ & $\mathrm{CS}, \mathrm{RTX}, \mathrm{LFT}$ & $\mathrm{R}$ & 1 \\
\hline 24 & 26 & $\mathrm{CS}$ & $\mathrm{CS}$ & $\mathrm{R}$ & $\mathrm{R}$ \\
\hline 25 & 27 & NR & NR & NR & NR \\
\hline 26 & 28 & $\mathrm{CS}$ & $\mathrm{CS}$ & I & $\mathrm{R}$ \\
\hline 27 & 29 & $\mathrm{CS}$ & CS, HCQ, SSZ & 1 & 1 \\
\hline 28 & 30 & NR & DMARD, CS & NR & 1 \\
\hline 29 & 31 & NR & NR & NR & NR \\
\hline 30 & 32 & CS & $\mathrm{CS}, \mathrm{ADA}, \mathrm{LFT}$ & NR & NR \\
\hline 30 & 33 & $\mathrm{CS}$ & NR & 1 & NR \\
\hline 31 & 34 & NR & NR & NR & NR \\
\hline 32 & 35 & $\mathrm{CS}$ & CS, CTX, MTX & $\mathrm{R}$ & 1 \\
\hline 33 & 36 & $\mathrm{CS}$ & $\mathrm{CS}$ & $\mathrm{R}$ & NR \\
\hline Current & $37^{a}$ & CS & RTX,CS & 1 & I \\
\hline
\end{tabular}


Table 3 Patient therapeutic coarse and outcomes (continued)

\begin{tabular}{|c|c|c|c|c|c|}
\hline \multirow[b]{2}{*}{ Citation no. } & \multirow[b]{2}{*}{ Case no. } & \multicolumn{2}{|l|}{ Treatment } & \multicolumn{2}{|c|}{ Outcomes } \\
\hline & & Immediate & Maintenance & Clinical & Radiologic \\
\hline 34 & 38 & RTX, MTX, CS & RTX,MTX & 1 & 1 \\
\hline 35 & 39 & CS & MTX, TCZ & $\mathrm{R}$ & 1 \\
\hline
\end{tabular}

Abbreviations: $A D A$ = adalimumab; $C S$ = corticosteroid; $D c$ = decreased; DMARD = disease-modifying antirheumatic drug; HCQ = hydroxychloroquine; IVIG = intravenous immunoglobulins; LFT = leflunomide; MMF = mycophenolate mofetil; I = improved; MTX = methotrexate; NR = not reported; NC = no change; $\mathrm{R}=$ resolved; RTX = rituximab; SSZ = sulfasalazine, AZA = azathioprine; TCZ = tocilizumab; $\mathrm{W}=$ worse; $\mathrm{VP}=$ ventriculoperitoneal shunt.

${ }^{a}$ The present case.

${ }^{\mathrm{b}}$ Improved, but with relapse of disease.

literature, ${ }^{34}$ an IL-6 inhibitor, tocilizumab, was added as a means to control RA joint symptoms after initial resolution of RM symptoms (seizures in this case) with steroid pulse therapy. The patient in this case remained seizure-free 2 years after therapy. It appears that tocilizumab may have played a critical role in treatment of RM in this case as well.

The present review reflects to an extent a shift in the classic paradigm of RA as a predominantly polyarthritic, generally symmetrical, sustained (greater than 6 weeks), upper and lower extremity idiopathic synovitis, all these criteria dominating early criteria sets for diagnosis or classification of RA. This would also seem the case with RM, as several patients in the current series developed RM at a time when the patient's RA was either inactive or yet undiagnosed.

Because patients with RA in the modern era may receive for their disease a number of immunosuppressive medications that can predispose to fungal, mycobacterial, and other infections, it is essential that a patient with RA presenting with meningitis be tested extensively to rule out such infections before being treated with yet more immunosuppressive medications. For at least one such drug, methotrexate, rheumatoid nodule formation can be accelerated, and others

\section{TAKE-HOME POINTS}

$\rightarrow$ Rheumatoid meningitis typically presents as a focal neurologic deficit or confusion.

$\rightarrow$ Prevalence seems to be higher in women.

$\rightarrow$ Leptomeningeal enhancement on MRI is a common finding.

$\rightarrow$ Patients seem to be responsive to corticosteroid initiation and maintenance therapy.

$\rightarrow$ Rates of successful remission-free treatment have increased since the Kato et al. review in the year 2000. may do so too. ${ }^{37,38}$ In all immunosuppressed patients, it is imperative that infectious etiologies be assiduously ruled out so that RM in such patients becomes a diagnosis of exclusion.

The prevalence of RA in the general population is approximately $1 \%$. Given that patients who develop RA can have positive serologic tests for it decades before synovitis begins and that several cases reported herein had RM diagnosed before their RA, it would be reasonable to suggest that anyone presenting with meningitis of unknown etiology be tested for the presence in serum of both RF and antibodies to cyclic citrullinated peptides.

In addition to raising awareness for RM among physicians who will likely see patients with neurologic complaints, we are also suggesting that more clinicians share their experiences with RM, especially those who use rituximab or alternative therapies. Hopefully, one day we can have a more complete chapter on the matter to include treatment algorithms and high specificity prognostic factors.

\section{Study funding}

No targeted funding reported.

\section{Disclosure}

The authors report no disclosures relevant to the manuscript. Full disclosure form information provided by the authors is available with the full text of this article at Neurology.org/cp.

\section{Publication history}

Received by Neurology: Clinical Practice December 31, 2018. Accepted in final form March 8, 2019.

Appendix Authors

\begin{tabular}{lll}
\hline Name & Location & Contribution \\
\hline Zhaoyi Qin, MD & $\begin{array}{l}\text { University of Kentucky } \\
\text { College of Medicine, } \\
\text { Lexington, KY; Kettering } \\
\text { Medical Center, Kettering, } \\
\text { OH }\end{array}$ & $\begin{array}{l}\text { Study design, literature } \\
\text { review, initial manuscript } \\
\text { draft, and manuscript } \\
\text { revision }\end{array}$ \\
\hline June Kim, MD & $\begin{array}{l}\text { University of Kentucky } \\
\text { College of Medicine, } \\
\text { Lexington, KY }\end{array}$ & $\begin{array}{l}\text { Radiology review and } \\
\text { image interpretation }\end{array}$ \\
& & \\
\hline
\end{tabular}


Appendix (continued)

\begin{tabular}{lll}
\hline Name & Location & Contribution \\
\hline $\begin{array}{l}\text { Damian } \\
\text { Valencia, MD }\end{array}$ & $\begin{array}{l}\text { Kettering Medical Center, } \\
\text { Kettering, OH }\end{array}$ & $\begin{array}{l}\text { Initial manuscript draft, } \\
\text { manuscript formatting, } \\
\text { review and revision, and } \\
\text { corresponding author }\end{array}$ \\
$\begin{array}{lll}\text { Lames } \\
\text { Hamoodi, MD }\end{array}$ & $\begin{array}{l}\text { University of Kentucky } \\
\text { College of Medicine, } \\
\text { Lexington, KY }\end{array}$ & $\begin{array}{l}\text { Pathology review and } \\
\text { histologic interpretation }\end{array}$ \\
$\begin{array}{lll}\text { Jana Neltner, } \\
\text { MD }\end{array}$ & $\begin{array}{l}\text { University of Kentucky } \\
\text { College of Medicine, } \\
\text { Lexington, KY }\end{array}$ & $\begin{array}{l}\text { Pathology review and } \\
\text { histologic interpretation }\end{array}$ \\
\hline $\begin{array}{l}\text { Travis } \\
\text { Mizemore, DO, }\end{array}$ & $\begin{array}{l}\text { University of Kentucky } \\
\text { College of Medicine, } \\
\text { Lexington, KY }\end{array}$ & $\begin{array}{l}\text { Review of literature and } \\
\text { rheumatologic case } \\
\text { discussion }\end{array}$ \\
\hline $\begin{array}{l}\text { Robert } \\
\text { Lightfoot Jr, MD }\end{array}$ & $\begin{array}{l}\text { University of Kentucky } \\
\text { College of Medicine, } \\
\text { Lexington, KY }\end{array}$ & $\begin{array}{l}\text { Principal investigator, } \\
\text { supervising attending } \\
\text { physician, and final } \\
\text { manuscript review }\end{array}$ \\
\hline
\end{tabular}

\section{References}

1. Yücel A, Kart H, Aydin A, et al. Pachymeningitis and optic neuritis in rheumatoid arthritis: successful treatment with cyclophosphamide. Clin Rheumatol 2001;20:136-139.

2. Cellerini M, Gabbrielli S, Bongi S, Cammelli D. MRI of cerebral rheumatoid pachymeningitis: report of two cases with follow-up. Neuroradiology 2001;43:147-150.

3. Kato T, Ken-ichi H, Yoshiki S, et al. Rheumatoid meningitis: an autopsy report and review of the literature. Clin Rheumatol 2003;22:475-480.

4. Chowdhry V, Kumar N, Lachance D, Salomao D, Luthra H. An unusual presentation of rheumatoid meningitis. J Neuroimaging 2005;15:286-288.

5. Thompson M, Mayer D. Rheumatoid pachymeningitis presenting with left-sided weakness. Mayo Clinic Proc 2005;80:500.

6. Ahmed M, Luggen M, Herman J, et al. Hypertrophic pachymeningitis in rheumatoid arthritis after adalimumab administration. J Rheumatol 2006;33:2344-2346.

7. Claassen J, Dwyer E, Maybaum S, Elkind M. Rheumatoid leptomeningitis after heart transplantation. Neurology 2006;66:948-949.

8. Chou R, Henson J, Tian D, Hedley-Whyte E, Reginato A. Successful treatment of rheumatoid meningitis with cyclophosphamide but not infliximab. Ann Rheum Dis 2006;65:1114-1116.

9. Zheng R, LV H, Zhang W, Yu M, Yuan Y. Rheumatoid leptomeningitis: a case report and literature review. J Peking University (Health Sciences) 2006;38:324-325.

10. Starosta M, Brandwein S. Clinical manifestations and treatment of rheumatoid pachymeningitis. Neurology 2007;68:1079-1080.

11. Shimada K, Matsui T, Kawakami M, et al. Diffuse chronic leptomeningitis with seropositive rheumatoid arthritis: report of a case successfully treated as rheumatoid leptomeningitis. Mod Rheumatol 2009;19:556-562.

12. Schmid L, Muller M, Treumann T, et al. Induction of complete and sustained remission of rheumatoid pachymeningitis by rituximab. Arthritis Rheum 2009;60: $1632-1634$.
13. Koide R, Isoo A, Ishii K, Uruha A, Bandoh M. Rheumatoid leptomeningitis: rare complication of rheumatoid arthritis. Clin Rheumatol 2009;28:1117-1119.

14. Kurne A, Karabudak R, Karadag O, et al. An unusual central nervous system in volvement in rheumatoid arthritis: combination of pachymeningitis and cerebral vasculitis. Rheumatol Int 2008;29:1349-1353.

15. Ii Y, Kuzuhara S. Rheumatoid cranial pachymeningitis successfully treated with longterm corticosteroid. Rheumatol Int 2008;29:583-585.

16. Matsushima M, Yaguchi $\mathrm{H}$, Niino $\mathrm{M}$, et al. MRI and pathological findings of rheumatoid meningitis. J Clin Neurosci 2010;17:129-132.

17. Ikeda $\mathrm{K}$, Takazawa $\mathrm{T}$, Ito $\mathrm{H}$, et al. Rheumatoid leptomeningitis: radiological alteration of cerebral hypoperfusion and subarachnoid lesions. Intern Med 2010;49:1911-1916.

18. Inan A, Masatlıoglu S, Ozyurek S, Engin D, Erdem I. Unusual central nervous system involvement of rheumatoid arthritis: successful treatment with steroid and azathioprine. Rheumatol Int 2009;31:1383-1385.

19. Servioli M, Chugh C, Lee J, Biller J. Rheumatoid meningitis. Front Neurol 2011;2 $1-4$.

20. Kim H, Park J, Oh H, Han H, Shin D, Kim M. A case of rheumatoid meningitis: pathologic and magnetic resonance imaging findings. Neurol Sci 2011;32:1191-1194.

21. Aguilar-Amat M, Abenza-Abildu M, Vivancos F, et al. Rheumatoid meningitis mimicking progressive supranuclear palsy. Neurologist 2011;17:136-140.

22. Hasiloglu Z, Askik M, Erer B, Dikici A, Altintas A, Albayram S. Magnetic resonance imaging of rheumatoid meningitis: a case report and literature review. Rheumatol In 2012;32:3679-3681

23. Huys A, Guerne P, Horvath J. Rheumatoid meningitis occurring during adalimumab and methotrexate treatment. Joint Bone Spine 2012;79:90-92.

24. Krysl D, Zamecnik J, Senolt L, Marusic P. Chronic repetitive nonprogressive epilepsia partialis continua due to rheumatoid meningitis. Seizure 2013;22:80-82.

25. Cuinat L, Nasr N, Kamsu J, Tanchoux F, Bonneville F, Larrue V. Meningeal disease masquerading as transient ischemic attack. J Stroke Cerebrovasc Dis 2014;23: $1738-1743$.

26. Hayashi Y, Namekawa M, Ohtani K, Watanabe E, Nakano I. Parkinsonism as an initial manifestation of rheumatoid meningitis. Neurol Sci 2014;35:1139-1141.

27. Bourgeois P, Rivest J, Bocti C. Rheumatoid meningitis presenting with stroke-like episodes. Neurology 2014;82:1564-1565.

28. Rijkers K, Postma A, Riedl R, Schijns O. Rheumatoid arthritis mimicking an intracranial malignancy. Acta Neurochirurgica 2013;156:427-428.

29. Yeaney G, Denby E, Jahromi B, Mangla R. Rheumatoid-associated meningitis and vasculopathy. Neurology 2015;84:1717-1718

30. Magaki S, Chang E, Hammond R, et al. Two cases of rheumatoid meningitis. Neuropathology 2015;36:93-102.

31. Koopmansch C, D’Haene N, Hastir D, Sadeghi N, Maris C, Salmon I. A 63-year-old woman with a right frontal lesion. Brain Pathol 2016;26:555-556.

32. Nihat A, Chinthapalli K, Bridges L, Johns P, Sofat N, Moynihan B. Rheumatoid meningitis. Pract Neurol 2016;16:312-314

33. Seago S, Stroberg E, Metting A. Rheumatoid meningitis associated with infliximab. Proc (Bayl Univ Med Cent) 2016;29:204-206.

34. Degboé Y, Fajadet B, Laurent C, Cantagrell A, Constantin A, Ruyssen-Witrand A. A rare case of rheumatoid pachyleptomeningitis successfully treated with rituximab. Rheumatology 2017;56:1238-1240.

35. Tsuzaki K, Nakamura T, Okumura H, Tachibana N, Hamano T. Rheumatoid meningitis occurring during etanercept treatment. Case Rep Neurol Med 2017; 2017:1-5.

36. Sokoloff L, McCluskey R, Bunim J. Vascularity of the early subcutaneous nodule of rheumatoid arthritis. AMA Arch Pathol 1953;55:475-495.

37. Holers V, Deane K. Preclinical features of rheumatoid arthritis. In: Hochberg M Silman A, Smolen J, Weinblatt M, Weisman M, editors. Rheumatology, 6th ed. Philadelphia: Elsevier; 2015:700.

38. Luger T. Chapter 33, skin in rheumatic disease. In: Hochberg M, Silman A, Smolen J, Weinblatt M,Weisman M, editors. Rheumatology, 6th ed. Philadelphia: Elsevier; 2015:255. 